\title{
Utilization of Satellite-based Remote-sensing for the Representation of External Boundary Conditions in Building Energy Modelling
}

\author{
Pelin Firat Ors ${ }^{1}$, Milena Vuckovic ${ }^{2}$, Ardeshir Mahdavi ${ }^{1}$ \\ ${ }^{1}$ Department of Building Physics and Building Ecology, TU Wien, Vienna, Austria \\ ${ }^{2}$ Center for Energy, AIT Austrian Institute of Technology GmbH, Vienna, Austria
}

\begin{abstract}
Microclimatic conditions in the urban domain show a high degree of variability, which may not be fully captured with terrestrial weather station networks. Relying on the use of weather station data as external boundary conditions may therefore cause deviations in simulation-supported energy assessment inquiries. This contribution addresses this issue by exploring the application potential of satellite-based thermal remote sensing data for more realistic representations of external microclimatic boundary conditions in building energy modelling. For this purpose, three different remote sensing datasets are compared with the air temperature observations from terrestrial weather stations. Our findings indicate a significant relationship between remote sensing data and air temperature observations with $0.901 \mathrm{R}^{2}$, and up to $0.938 \mathrm{R}^{2}$ in individual dataset comparisons. Moreover, air temperature is estimated from satellite-acquisitions with an overall RMSE of $2.96 \mathrm{k}$.
\end{abstract}

\section{Introduction}

Urban areas represent highly dynamic thermal environments and display significantly diverse microclimatic characteristics. Temperature information obtained from terrestrial weather stations may not be sufficient for representing the actual thermal profiles within cities due to this microclimatic complexity (Barnaby and Crawley, 2011) and sparse distribution of weather stations within meteorological networks. This may result in use of unrealistic external boundary conditions in building energy modelling efforts. Hence, the reliability of simulation-supported energy assessments in urban environments could be negatively affected (Vuckovic et al., 2017; Pernigotto et al., 2014).

This contribution addresses this issue by exploring the applicability of satellite-based thermal remote sensing data for more realistic representations of external microclimatic boundary conditions in building energy modelling. This is motivated by the fact that satellitebased thermal remote sensing method is capable of providing instantaneous temperature information over large study areas, such as whole cities. By establishing a direct relationship between satellite-based thermal data and near-surface air temperatures, it may be possible to gain more realistic insights regarding the thermal profiles within cities and increase the representability of external boundary conditions in building energy modelling efforts.
For this purpose, we focus on city of Vienna, Austria, as our case study.

\section{Study area}

Vienna is a Central European city. It is located in the North-East part of Austria. The city is situated on both sides of Danube River, which flows from north-west to south-east. The city centre of Vienna is rather flat and has an altitude of $171 \mathrm{~m}$. The highest point within the municipal boundary $(543 \mathrm{~m})$ is located on North-West part of the city, while the lowest point $(151 \mathrm{~m})$ is located at a floodplain area of Danube on South-East (City of Vienna, 2018). The city experiences a relatively humid temperate climate which carries the characteristics of CFB class of Köppen - Geiger Climate Classification (Kottek et al., 2006).

The population of Vienna is about 1.9 million, with 4600 people per $\mathrm{km}^{2}$ average density. While this ratio is 27660 people per $\mathrm{km}^{2}$ in a centrally located district (Margareten), it is 1440 people per $\mathrm{km}^{2}$ in a more peripheral district such as Hietzing (Vienna in Figures, 2018). This variation implies a differentiation in built environment characteristics within the city, which has been extensively explored and documented by several previous research efforts (Mahdavi et al., 2014; Vuckovic et al., 2017; 2015; Hammerberg et al., 2018).

This contribution relies on the findings from these efforts concerning the structure, variation, and distribution of built environment typologies in the study area. Specifically, it explores

- how thermal remote sensing data (hereafter ST) relate to air temperature observations (hereafter WS) within the study area,

- if and how a relationship can be established to calculate air temperatures from ST data,

- if and how the built environment characteristics influence the relationship between the ST data and corresponding WS observations.

\section{Terrestrial weather stations}

Hourly air temperature data from seven terrestrial stationary weather stations are used in this study, namely, Innere Stadt, Donaufeld, Hohe Warte, Mariabrunn, Schwechat, Seibersdorf and Gross-Enzersdorf (Figure 1, Table 1). The locations of the selected weather stations represent both densely and sparsely occupied areas, and they are located inside or at the surrounding area of 


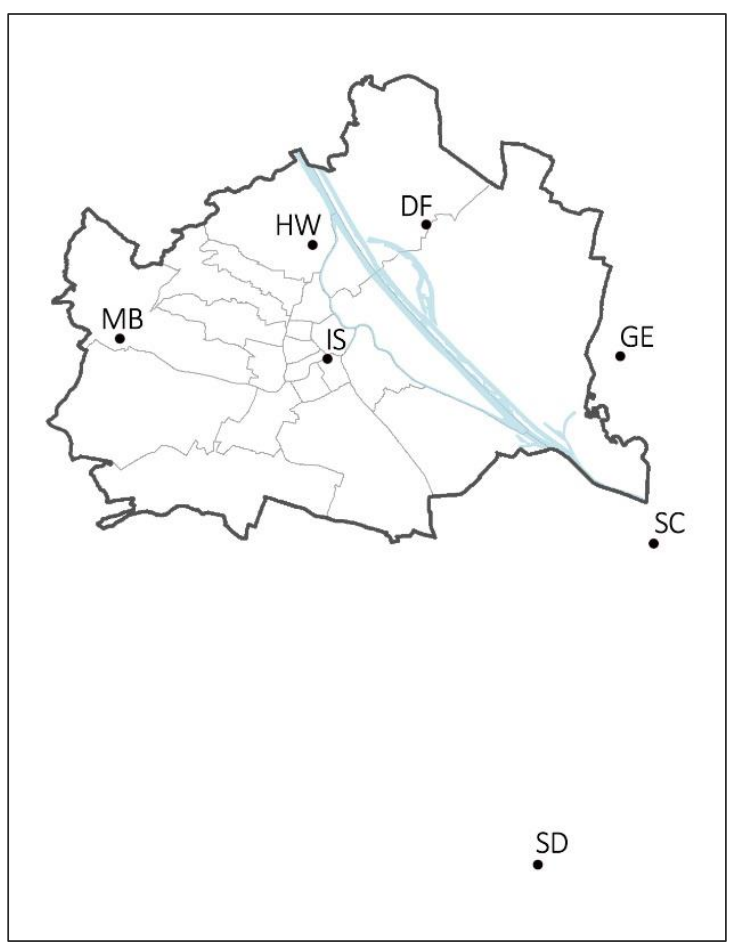

Figure 1: The locations of terrestrial weather stations. (Figure generated with data from OGD Vienna (2019).)

Vienna. Vuckovic et al. (2017) presented a detailed overview regarding the environmental characteristics of these locations (except for Gross-Enzersdorf) through the concept of "urban units of observation (U2Os)" (Mahdavi et al., 2013) and allocated them into "local climate zone (LCZ)" classes (Stewart and Oke, 2012).

WS data used for this study was obtained from terrestrial stationary weather stations operated by Central Institute of Meteorology and Geodynamics (Zentralanstalt für Meteorologie und Geodynamik, ZAMG). ZAMG provides high-class climate data which has been evaluated for data quality with a number of tests. These tests include a real-time control to detect large discrepancies during the time of acquisition, as well as the utilization of Austria Quality Service (AQUAS) software to screen, mark, and eliminate anomalous data. The data is stored in the climatic database after the final checks are performed and data verification is confirmed by an examiner. ZAMG also carries out screening and verification process of historical climate data records. The historical records are evaluated by means of Data Correction Tool (DCT) with several test steps before they are verified and stored
(ZAMG, 2019). Based on this information, WS data used in this contribution has a consistent and good quality across different terrestrial weather stations and is thus appropriate for comparison purposes.

\section{Satellite-based thermal remote sensing}

Three main satellite-based thermal remote sensing datasets with different spatial and temporal resolutions as well as processing levels were selected for the present contribution. Details regarding these datasets are presented in Table 2.

\section{MODIS LST data}

The first dataset consists of daytime land surface temperature (LST) data from MOD11_L2 V006 (version 6) product (hereafter $\mathrm{ST}_{\mathrm{M}}$ ) of Moderate Resolution Imaging Spectroradiometer (MODIS) Sensor of Terra Satellite (Wan et al., 2015). It is provided by Land Processes Distributed Active Archive Center (LP DAAC) which is an Earth Observing System Data and Information System (EOSDIS) Distributed Active Archive Center (DAAC) under the NASA Earth Science Data and Information System (ESDIS) project (LP DAAC, 2019). MODIS images used in this study is retrieved from the Earth Explorer website provided by USGS (EarthExplorer, 2019).

$\mathrm{ST}_{\mathrm{M}}$ data is generated from 5-minute satellite acquisitions (MODIS, 2019) and has been selected for this study because of the frequent revisit time of MODIS and thus good data availability. The data has a spatial resolution (pixel size) of about $1000 \mathrm{~m}$ with a revisit time of $1-2$ days. It offers per-pixel LST values together with emissivity, and acquisition-based information on data quality, LST error, view time, view angle and geolocation. Cloud contaminated LST pixels are excluded from $\mathrm{ST}_{\mathrm{M}}$ products, they are distributed as cloudscreened. The data availability period is from February 2000 to present (MODIS, 2019).

Image selection for this contribution was carried out based on three different criteria. In the first step, when possible, MODIS images were selected, which were acquired on the same dates as Landsat 7 ETM+ images used for this study. This decision was based on the close acquisition times of Landsat 7 and daytime Terra over an area. Both satellites have been sent into the same orbit and they have close equatorial crossing times (Landsat 7, 10:00 a.m. \pm 15 minutes; Terra 10:30 a.m.). Therefore, their acquisitions over a given area on Earth are close to

Table 1: Information on selected terrestrial weather stations.

\begin{tabular}{ccccccc}
\hline Name & Abbreviation & Longitude & Latitude & Altitude $(\mathbf{m})$ & Sensor Height $(\mathbf{m})$ & LCZ \\
\hline Innere Stadt & IS & 16.366 & 48.198 & 177 & 9.3 & 2 \\
\hline Hohe Warte & HW & 16.356 & 48.249 & 198 & 1.9 & 6 \\
\hline Donaufeld & DF & 16.431 & 48.257 & 160 & 2 & 6 \\
\hline Mariabrunn & MB & 16.229 & 48.207 & 225 & 1 & 9 \\
\hline Groß-Enzersdorf & GE & 16.559 & 48.200 & 154 & 2.1 & D \\
\hline Schwechat & SC & 16.582 & 48.117 & 183 & 2.2 & $D_{E}$ \\
\hline Seibersdorf & SD & 16.505 & 47.976 & 185 & 2.1 & 8 $_{\mathrm{D}}$ \\
\hline
\end{tabular}


Table 2: Information on selected remote sensing datasets.

\begin{tabular}{clccc}
\hline Satellite & Sensor & Data Product & Spatial Resolution (m) & Revisit Time (days) \\
\hline Terra & MODIS & MOD11_L2 V006 (ST $\left.{ }_{M}\right)$ & 1000 & $1-2$ \\
\hline Landsat 7 & ETM+ & TOA BT (ST $\left.{ }_{B}\right)$ & 60 (Resampled to 30) & 16 \\
\hline Landsat 7 & ETM+ & LST (ST $)$ & 60 (Resampled to 30) & 16 \\
\hline
\end{tabular}

each other (Landsat, 2018). In this context, using images from the same dates for the study increases the similarity of the meteorological conditions of the selected dates and enhance data comparability. Secondly, image selection was performed so that the minimum of ten images per each month of the year were selected. This was done in order to have a more representative set of observations across different seasons. Thirdly, images were selected, which accommodate the first two criteria and have better data availability over the study area in terms of clear sky conditions. All in all, a total of $126 \mathrm{ST}_{\mathrm{M}}$ images were obtained, which had been acquired during daytime between the years 2000 and 2015 .

$\mathrm{ST}_{\mathrm{M}}$ products are distributed in HDF-EOS (Hierarchical Data Format - Earth Observing System) file format (MODIS, 2019). HDF-EOS files must be converted into GeoTIFF, and data must be processed into a projection system to be recognized by most of the available GIS tools (HEG, 2017). Obtained $\mathrm{ST}_{\mathrm{M}}$ images were therefore converted into GeoTIFF and projected into Universal Transverse Mercator (UTM) projection, by using HEG (HDF-EOS to GeoTIFF Conversion Tool, HEG). Google Earth Engine (GEE), a cloud-based analysis platform for geospatial data, was used for conducting further analyses of the $\mathrm{ST}_{\mathrm{M}}$ images (Gorelick et al., 2017). As $\mathrm{ST}_{\mathrm{M}}$ products are currently not included in the existing dataset repository within GEE, the GeoTIFF files were uploaded to the platform as assets via GEE code editor. LST band of $\mathrm{ST}_{\mathrm{M}}$ product is provided by LP DAAC as scaled, similar to most of the other bands. The data stored in the bands must be multiplied by a certain scaling factor before interpretation. The scaling factor varies across different bands of the product, which is 0.02 for the LST band (MODIS, 2019). Therefore, the LST bands of the images were scaled accordingly to attain per-pixel LST in $\mathrm{k}$. Subsequently, the data was further processed to attain perpixel LST values in ${ }^{\circ} \mathrm{C}$. After finishing the image adjustments, selected weather station locations were entered by specifying their latitude and longitude information. They have been defined with point geometry in GEE, which later served as data extraction points to obtain pixel-based LST values at their locations. These LST values were extracted for each image and exported with .csv format into Google Drive for further statistical analyses.

\section{Landsat 7 ETM+ data}

Two Landsat 7 ETM+ datasets with different processing/correction levels were also selected for this study because of their favourable spatial resolution of $30 \mathrm{~m}$ (originally acquired at $60 \mathrm{~m}$ ) for urban climate studies. These were Top of Atmosphere (TOA)
Brightness Temperature (BT) data (hereafter $\mathrm{ST}_{\mathrm{B}}$ ), which was accessed through USGS Landsat 7 Surface Reflectance (SR) Tier-1 dataset from GEE repository and Land Surface Temperature data (hereafter $\mathrm{ST}_{\mathrm{L}}$ ), which was estimated by and accessed through a web application developed by Parastatidis et al. (2017).

Landsat 7 ETM+ has a revisiting time of 16 days with a spatial resolution of $60 \mathrm{~m}$ (thermal band) (Landsat, 2018). Landsat data is provided with different pre-processing levels to correct for instrumental, solar, atmospheric and topographic artefacts (Young et al., 2017). $\mathrm{ST}_{\mathrm{B}}$ data used in this study is offered within the Surface Reflectance product, which is a Landsat Science Product provided by USGS (USGS, 2019). Landsat Science Products are introduced to minimize the need for user performed corrections to the Landsat data and are undergone advanced pre-processing steps prior to distribution (LEDAPS, 2018). Therefore, $\mathrm{ST}_{\mathrm{B}}$ data used in this study is provided as orthorectified (GEE, 2019), and as corrected for instrumental artefacts (Young et al., 2017).

As stated earlier, USGS Landsat 7 Surface Reflectance Tier-1 dataset from GEE repository was used for obtaining $\mathrm{ST}_{\mathrm{B}}$ data. Although the repository contains both Tier-1 and Tier- 2 category $\mathrm{ST}_{\mathrm{B}}$ data, Tier-1 category consists of the highest quality Landsat images with sufficient radiometric calibration and geolocational accuracy for time-series analysis (Landsat Collections, 2019). Therefore, only Tier-1 data was selected to be used in this study.

GEE platform was used for analysing $\mathrm{ST}_{\mathrm{B}}$ data. As a first step, data filtering was conducted over USGS Landsat 7 Surface Reflectance Tier 1 image collection. The data was filtered based on date, location (path/row) and cloud cover. In the end, a total of 57 images was selected, acquired between 01.01.2000 and 31.12.2015 with maximum $20 \%$ cloud cover from WRS-2 Path 190 and Row 26. Secondly, BT band of the SR product was selected and scaled using the scale factor provided by USGS to obtain per-pixel BT values in $\mathrm{k}$. The data was later converted into ${ }^{\circ} \mathrm{C}$. After the image processing was complete, weather station locations were defined with point geometries by entering their latitude and longitude information into GEE code editor. Pixel BT values of these locations were later extracted for each image into a .csv file to be used for further analyses.

Although $\mathrm{ST}_{\mathrm{B}}$ is corrected for instrumental effects, it does not provide the land surface temperature information. Hence, an additional level of processing is required, namely the correction for atmospheric effects (Young et al., 2017). It is generally not easy and straightforward to remove these effects from Landsat images and obtain LST 
data. A certain level of user expertise, and introduction of additional atmospheric information is usually necessary (Parastatidis et al., 2017). Currently, USGS provides a "Level-2 Provisional Surface Temperature" product only for U.S., Alaska and Hawaii regions (Landsat Science, 2019). Since the main focus of this present contribution is to explore the applicability of satellite-based thermal data as external microclimatic boundary conditions in simulation-supported building energy performance inquiries, ease of access to remote sensing data is an important parameter. Landsat 7 ETM+ thermal data is a valuable data source for urban climate studies with its $60 \mathrm{~m}$ resolution acquisitional capabilities. It provides a better opportunity to capture micro-climatic tendencies in urban environments with respect to many other available remote sensing data sources, such as MODIS. Based on these considerations, $\mathrm{ST}_{\mathrm{L}}$ data for this study was decided to be obtained from a web-based tool developed by Parastatidis et al. (2017), which provides estimated LST data from Landsat acquisitions (Landsat 5,7,8) (Remote_Sensing, 2019). The tool requires the users to define their region of interest and select from one of the available emissivity sources based on their needs to perform the LST estimation. The estimation is carried out by using Google cloud servers and GEE dataset repository, and LST data is provided with an overall root mean squared error (RMSE) of $1.52{ }^{\circ} \mathrm{C}$ (tested against Terra ASTER LST data and Landsat LST data calculated by other techniques) (Parastatidis et al., 2017).

$\mathrm{ST}_{\mathrm{L}}$ data was obtained for the same dates and for the same locations as the $\mathrm{ST}_{\mathrm{B}}$ data used in this study. The obtained GeoTIFF images from the afore-mentioned application by Parastatidis et al. (2017) was uploaded to GEE as assets. Since the data was provided as scaled, cloud-screened, and in ${ }^{\circ} \mathrm{C}$, no additional adjustments were necessary. LST data was extracted for the weather station locations from each image, and the values were exported in .csv format to Google Drive to be prepared for further processing.

\section{Statistical analyses}

All in all, a total of $126 \mathrm{ST}_{\mathrm{M}}, 57 \mathrm{ST}_{\mathrm{B}}$ and $57 \mathrm{ST}_{\mathrm{L}}$ daytime images were obtained for the study. Acquisition times of images were around 09:30 - 09:45 GMT for $\mathrm{ST}_{\mathrm{B}}$ and $\mathrm{ST}_{\mathrm{L}}$, and 09:40 - 10:25 GMT for $\mathrm{ST}_{\mathrm{M}}$. ST data corresponding to the pixels of weather station locations were extracted for each image for further analyses. WS data obtained from terrestrial weather stations were recorded at hourly intervals. To achieve a more time-sensitive comparison, the temporal resolution of the terrestrial data was increased into a 30-minute interval dataset via interpolation of the hourly data. Assignments of WS data from this dataset to each obtained per-pixel value of ST data was conducted.

\section{Exploring WS and ST datasets}

In order to see how ST and corresponding WS data relate to each other, a series of statistical inquiries were performed (Table 3). Linear regression analysis method was deployed for this purpose. Scatter diagrams of datasets were plotted. Coefficient of determination $\left(\mathrm{R}^{2}\right)$ values, together with the slopes and y-intercepts of the best-fitting lines were used to interpret how two datasets related to each other. The interpretation of the regression outcomes was performed based on the following principles. $\mathrm{R}^{2}$ values, which can take values in the range of $0-1$, indicate a lower variance if the $R^{2}$ value is greater (Moriasi et al., 2007, Taheri et al., 2013). Thus, higher $\mathrm{R}^{2}$ values were regarded by us as better indicators of agreement between ST and WS datasets. Slope and yintercept of the best-fitting line is a measure of how two compared datasets relate to each other. A perfect fit of two datasets are existent when slope is equal to 1 and $y$ intercept is equal to 0 (Moriasi et al., 2007; Willmott, 1984). The outcomes of the scatter diagrams plotted with ST and WS data were interpreted based on these notions in the following inquiries.

- Firstly, all acquired per-pixel temperature data from satellite images for all weather station locations (hereafter $\mathrm{ST}_{\mathrm{MLB}}$ ) were compared with the corresponding WS observations from terrestrial weather stations. The data was plotted into a scatter diagram to explore the relationship between the two datasets (Figure 2).

- For the second step, ST dataset was divided into three portions based on the product types; namely, $\mathrm{ST}_{\mathrm{M}}$ data, $\mathrm{ST}_{\mathrm{B}}$ data and $\mathrm{ST}_{\mathrm{L}}$ data. All three datasets were then individually compared with their corresponding WS observations from all terrestrial weather stations in order to explore how these individual remote sensing product types related to the WS observations. All three datasets were separately plotted into the same scatter diagram for comparison. In Figure 3, they are only represented with the best fitting lines for diagram readability.

These inquiries provided notable insights regarding how remotely sensed per-pixel temperature data, selected remote sensing products and corresponding terrestrial air

Table 3:Comparison of ST and WS datasets.

\begin{tabular}{ccccc}
\hline Datasets & Number of observations & Equation & Derived relationships & $\mathbf{R}^{\mathbf{2}}$ \\
\hline $\mathrm{ST}_{\mathrm{MLB}}-\mathrm{WS}$ & 1374 & 1 & $\mathrm{WS}=0.7572\left(\mathrm{ST}_{\mathrm{MLB}}\right)+0.1621$ & 0.901 \\
\hline $\mathrm{ST}_{\mathrm{M}}-\mathrm{WS}$ & 820 & 3 & $\mathrm{WS}=0.7742\left(\mathrm{ST}_{\mathrm{M}}\right)-0.3414$ & 0.938 \\
\hline $\mathrm{ST}_{\mathrm{L}}-\mathrm{WS}$ & 277 & 4 & $\mathrm{WS}=0.7041\left(\mathrm{ST}_{\mathrm{L}}\right)-0.4928$ & 0.920 \\
\hline $\mathrm{ST}_{\mathrm{B}}-\mathrm{WS}$ & 277 & 5 & $\mathrm{WS}=0.9096\left(\mathrm{ST}_{\mathrm{B}}\right)-0.4942$ & 0.905 \\
\hline
\end{tabular}




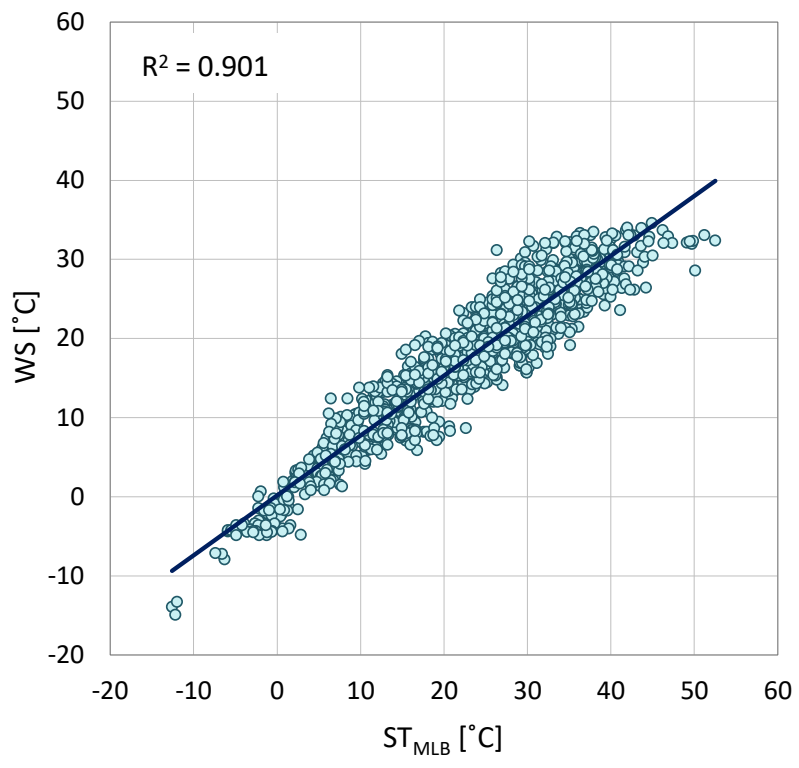

Figure 2: Comparison of WS and $S T_{M L B}$ datasets.

temperature observations relate to each other. A good agreement was observed in all investigated dataset pairs. $\mathrm{ST}_{\mathrm{B}}$ data display the lowest $\mathrm{R}^{2}(0.905)$, yet a good match to the measurements in terms of the respective regression equation's slope. On the other hand, the two LST datasets $\left(\mathrm{ST}_{\mathrm{M}}\right.$ and $\mathrm{ST}_{\mathrm{L}}$ ) temperature values were generally much higher than those of the terrestrial weather stations.

These observations are consistent and point to the influences of different pre-processing levels of TOA and LST products. As mentioned earlier, $\mathrm{ST}_{\mathrm{B}}$ data was not corrected for atmospheric influences. Therefore, the lower temperature range of this dataset may be due to the atmospheric attenuation effects. This circumstance may have compensated for the relative higher land surfaces during daytime with respect to the near-surface air temperatures (Voogt and Oke, 1997).

A better agreement of land surface temperatures with air temperatures during the night has been noted in previous studies (Krishnan et al., 2015; Pichierri et al., 2012) and attributed to the absence of solar effects (Pichierri et al., 2012). As mentioned earlier, LST retrieval from Landsat data is currently a challenging process. $\mathrm{ST}_{\mathrm{B}}$ data may be therefore a promising candidate for air temperature estimations due to its ease of access and the aforementioned favourable spatial resolution of Landsat 7 ETM+ instrument. According to our findings, the agreement of $\mathrm{ST}_{\mathrm{B}}$ data with the explored WS is promising for further inquiries regarding its spatial behaviour. But it still should be interpreted with caution when relating to the near-surface temperature information, given the aforementioned concerns regarding its processing level.

\section{Air Temperature calculations}

Outcomes from the previous statistical inquiries regarding near-surface air temperature observations and remote sensing datasets were utilized to derive a direct relationship to calculate air temperatures based on satellite acquisitions.

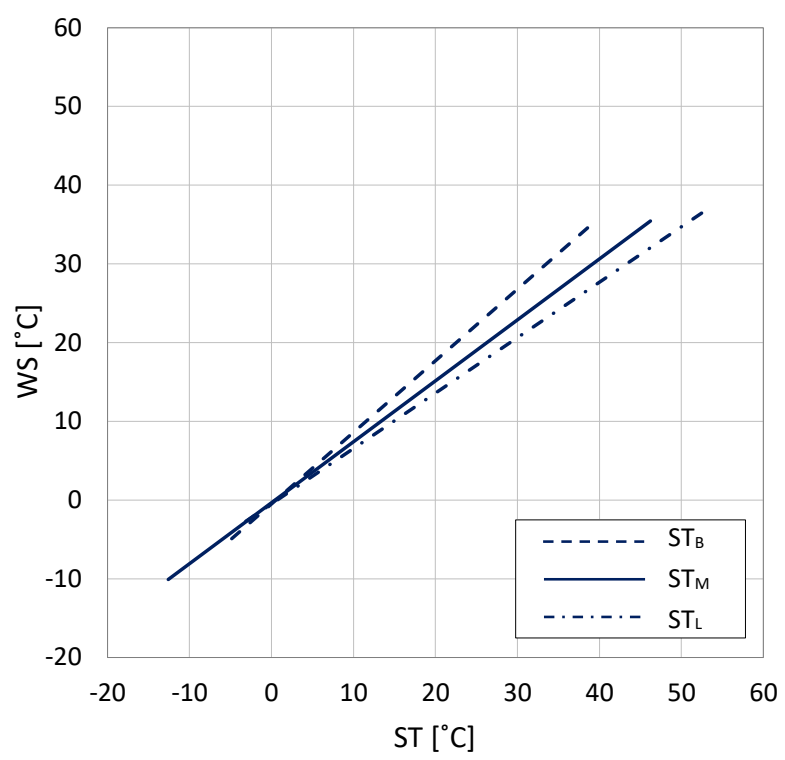

Figure 3: Comparison of WS and individual ST datasets.

With this purpose, in the first approach, a general equation was explored to calculate near-surface air temperature from remotely sensed per-pixel temperature data without differentiating between different remote sensing product types. Equation (1) was deployed for this purpose (Table 3 ). In order to evaluate the accuracy of calculated air temperature, a series of statistical tests were performed. First, air temperature information obtained from terrestrial weather stations (WS) was plotted against the corresponding calculated air temperature values (hereafter $\mathrm{WS}_{\mathrm{c}}$ ). Scatter-plot diagrams of these two datasets were generated. Coefficient of determination $\left(\mathrm{R}^{2}\right)$ value and the slope and $y$-intercept of the best fitting regression line were obtained. Five-number summary and root mean squared error (RMSE) metrics was also used to evaluate the proposed equation. For this purpose, an error dataset was computed by subtracting weather station observations from calculated terrestrial air temperatures. Likewise, the five-number summary of the error dataset was computed, and a box-plot diagram was used to interpret the distribution of values within the error dataset (Figure 4, Table 4).

After this step, Equation (1) was applied to three remote sensing products separately in order to explore how individual ST products respond to the proposed equation. RMSE and five-number summary were applied as described in the previous step to interpret the results (Figure 4, Table 4).

In the second part of the air temperature calculations, individual equations for different ST products were used to calculate near-surface air temperature information from their acquisitions. For this purpose, the best fitting linear equations presented in Table 3 were used. Equations (3), (4), and (5) were applied to the corresponding individual ST datasets. As described earlier, RMSE, five-number summary and box-plots of computed error-datasets were used to evaluate the proposed equations (Figure 4, Table 4). 


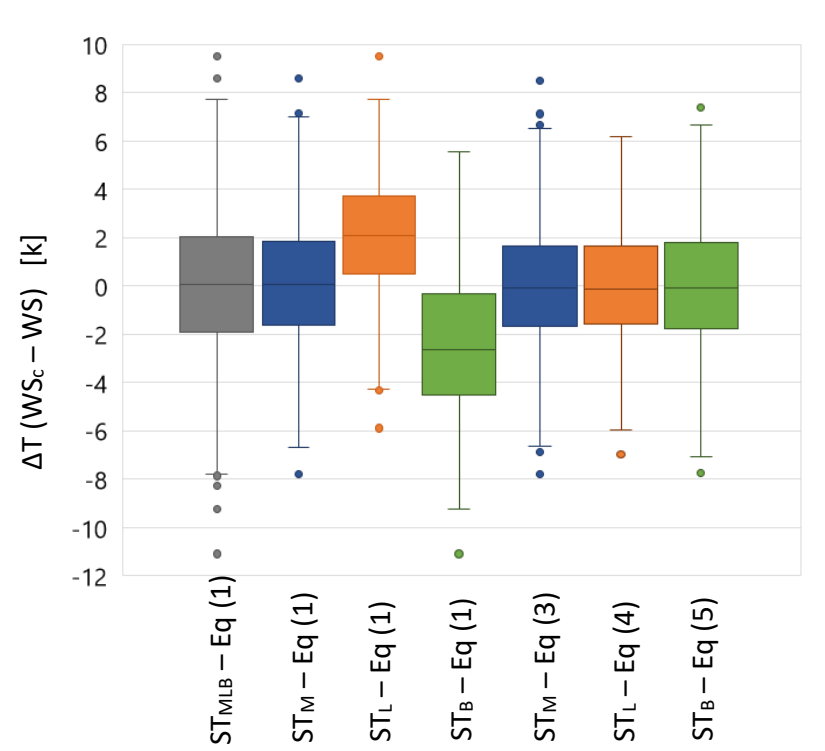

Figure 4: Results of different $W S_{c}$ calculation options.

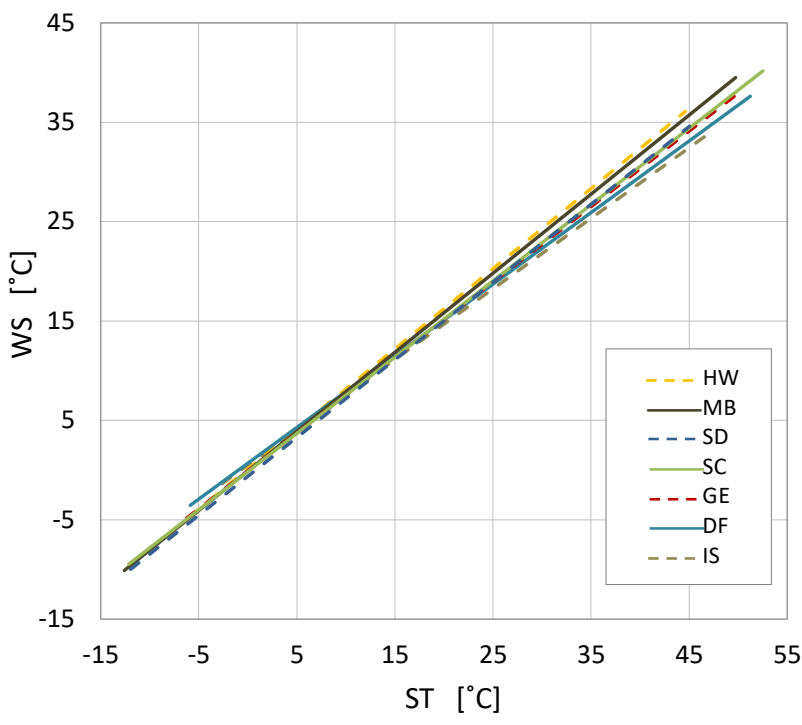

Figure 5: Location-based analysis of $W S-S T_{M L B}$.

Table 4: Relationships between $W S_{c}$ and WS for different ST datasets (see Table 3).

\begin{tabular}{cccccccc}
\hline & ST $_{\text {MLB }}$ & \multicolumn{2}{c}{$\mathbf{S T}_{\mathbf{M}}$} & \multicolumn{3}{c}{$\mathbf{S T}_{\mathbf{L}}$} & \multicolumn{2}{c}{ ST $_{\text {B }}$} \\
\cline { 2 - 9 } & Eq (1) & Eq (1) & Eq (3) & Eq (1) & Eq (4) & Eq (1) & Eq (5) \\
\hline RMSE (k) & 2.96 & 2.51 & 2.50 & 3.20 & 2.37 & 3.82 & 2.58 \\
\hline Min (k) & -11.09 & -7.77 & -7.78 & -5.88 & -6.99 & -11.09 & -7.73 \\
\hline Q1 (k) & -1.91 & -1.60 & -1.67 & 0.55 & -1.54 & -4.53 & -1.78 \\
\hline Q2 (k) & 0.06 & 0.06 & -0.08 & 2.07 & -0.13 & -2.65 & -0.09 \\
\hline Q3 (k) & 2.04 & 1.86 & 1.64 & 3.71 & 1.67 & -0.35 & 1.77 \\
\hline Max (k) & 9.52 & 8.60 & 8.48 & 9.52 & 6.20 & 5.54 & 7.41 \\
\hline
\end{tabular}

When the same equation, which was derived from the relationship presented in Figure 2, was applied to all individual ST datasets, the resulting RMSE values were 2.51, 3.20, and $3.82 \mathrm{k}$ for $\mathrm{ST}_{\mathrm{M}}, \mathrm{ST}_{\mathrm{L}}$ and $\mathrm{ST}_{\mathrm{B}}$ respectively. When the difference between $\mathrm{WS}_{\mathrm{c}}$ and corresponding WS values were computed, the median of the error datasets corresponded to 0.06 for $\mathrm{ST}_{\mathrm{M}}, 2.07$ for $\mathrm{ST}_{\mathrm{L}}$ and $-2.65 \mathrm{k}$ for $\mathrm{ST}_{\mathrm{B}}$. Our findings further indicated that introduction of the product-specific equations improved the air temperature calculations. This improvement was not quite pronounced for the $\mathrm{ST}_{\mathrm{M}}$ dataset, which might be because of the greater number of observation points available for the product due to the more frequent revisiting time of Terra Satellite. All in all, the best calculation results were associated with $\mathrm{ST}_{\mathrm{L}}$ product with a RMSE of $2.37 \mathrm{k}$ when the product-specific equation (Equation 4) was applied.

\section{Location-specific inquiries}

In the last part of the study, we explored how remotely sensed per-pixel temperatures and air temperature observations related to each other while considering the location of the weather stations. WS dataset was divided into seven parts based on different terrestrial weather stations and compared with all acquired per-pixel remote sensing data (Figure 5).
Innere Stadt (IS) is located in the densest urban setting among the weather station locations considered. According to the results of our comparison, IS presents a slightly cooler trend when compared with other locations. Since daytime MODIS and Landsat 7 ETM+ acquisitions are around 09:30 - 10:00 GMT over the study area, this lower temperature profile may be due to the existence of a cool island formation in that area resulting from the shading effects of the denser urban structure. Since urban thermal domain presents stronger overheating characteristics during the night, employment of nighttime remote sensing datasets may yield deeper insights regarding the relationship between air temperature and remote sensing data for different urban morphologies.

\section{Conclusion}

This contribution addressed the application potential of satellite-based thermal remote sensing data as a contributor to a richer representation of microclimatic boundary conditions for, amongst other things, building energy modelling efforts. The focus was to provide a straightforward procedure which did not require a deep level of processing and user expertise in the remote sensing domain. Ease of access to remote sensing products was therefore also an important criterion. For this purpose, temperature information from three different 
remote sensing datasets were compared with terrestrial weather station observations. Our findings point to a strong correlation between the air temperature data and thermal remote sensing data over the study area. We further explored the potential of calculating air temperature information from remote sensing data sources. Our results indicated an overall RMSE of $2.96 \mathrm{k}$ for all investigated datasets, as well as a lowest RMSE of $2.37 \mathrm{k}$ for individual remote sensing datasets. Derived relationships in this contribution can assist to relate how calculated air temperatures for a site location relate to the air temperature information from terrestrial weather stations networks in the city of Vienna. As temperature profile within a location shows a considerable degree of diurnal variation, these relationships were established for the acquisition times of the selected satellites. Our future work will focus on increasing the temporal interval of used remote sensing datasets within the diurnal cycle. This would assist the applicability of calculated air temperature information from remote sensing datasets as hourly input data in building-based energy assessment inquiries. For this purpose, addition of nighttime Terra MODIS (equatorial crossing time around 10:30 pm) and daytime/ nighttime Aqua MODIS (equatorial crossing time around 01:30pm and 01:30 am) LST products to the currently used datasets is planned in order to have a more enhanced diurnal dataset distribution (Earthdata, 2019). Our work will also focus on improving the error range of the purposed relationships and exploring their adaptability and performance at other locations. Introduction of auxiliary parameters (Zakšek and Schroedter-Homscheidt, 2009) and use of machine learning algorithms may assist further explorations of these datasets in other urban locations.

\section{References}

Barnaby, C.S., Crawley, D.B. (2011). Weather Data for Building Performance Simulation. In Hensen, J.L.M., Lamberts R. Building Performance Simulation for Design and Operation. Taylor \& Francis Group. New York (U.S.A.).

City of Vienna. (2018). Vienna geographical key data. https://www.wien.gv.at/statistik/lebensraum/tabellen/ stadtgebiet-eckdaten.html/. (accessed: January 27, 2019).

Earthdata. (2019). Nasa EOSDIS Earth Data. https://earthdata.nasa.gov/faq/. (accessed: April 10, 2019).

EarthExplorer. (2019). USGS Earth Explorer data access website. https://earthexplorer.usgs.gov/. (accessed: November 01, 2018).

GEE. (2019). Google Earth Engine. https://earthengine.google.com/. (accessed: November 01, 2018).

Gorelick, N., Hancher, M., Dixon, M., Ilyushchenko, S., Thau, D., and Moore, R. (2017). Google Earth Engine: Planetary-scale geospatial analysis for everyone. Remote Sensing of Environment 202, 18-27.
Hammerberg, K., Brousse, O., Martilli A. and Mahdavi, A. (2018). Impications of employing detailed urban canopy parameters for mesoscale climate modelling: A comparison between WUDAPT and GIS databases over Vienna, Austria. International Journal of Climatology 38(S1), 1241-1257.

HEG. (2017). HDF-EOS to GeoTIFF Conversion Tool (HEG) Stand-alone User's Guide. https://newsroom.gsfc.nasa.gov/sdptoolkit/HEG/HE G214/EED2-TP-030_HEG_UsersGuide_2.14.pdf/. (accessed: December 15, 2018).

Kottek, M., Grieser, J., Beck, C., Rudolf, B. and Rubel, F. (2006). World Map of the Köppen-Geiger climate classification updated. Meteorologische Zeitschrift 15(3), 259-263.

Krishnan, P., Kochendorfer, J., Dumas, E. J., Guillevic, P. C., Baker, C. B., Meyers, T. P. and Martos, B. (2015). Comparison of in-situ, aircraft, and satellite land surface temperature measurements over a NOAA Climate Reference Network site. Remote Sensing of Environment 165, 249-264.

Landsat. (2018). Landsat 7 Data Users Handbook. Department of the Interior. U.S. Geological Survey (USGS). https://www.usgs.gov/media/files/landsat-7data-users-handbook/. (accessed: April 10, 2019).

Landsat Collections. (2019). https://landsat.usgs. gov/what-are-landsat-collection-1-tiers/. (accessed: January 25, 2019).

Landsat Science. (2019). Landsat Science Products. https://www.usgs.gov/land-resources/nli/landsat/ landsat-provisional-surface-temperature?qt-science_ support_page_related_con=0\#qt-science_support_ page_related_con/. (accessed: January 25, 2019).

LEDAPS. (2018). Landsat 4-7 Surface Reflectance (LEDAPS) Product Guide. Department of the Interior. U.S. Geological Survey (USGS). https://www.usgs.gov/media/files/landsat-4-7-surface -reflectance-code-ledaps-product-guide/. (accessed: April 10, 2019).

LP DAAC. (2019). Land Processes Distributed Active Archive Center, LP DAAC. https://lpdaac.usgs.gov/. (accessed: January 15, 2019).

Mahdavi, A., Kiesel, K., \& Vuckovic, M. (2013). A framework for the evaluation of urban heat island mitigation measures. Proceedings from SB13 Munich: Implementing Sustainability - Barriers and Chances Conference, Munich (Germany), 24-26 April 2013.

Mahdavi, A., Kiesel, K. and Vuckovic, M. (2014). Empirical and computational assessment of the urban heat island phenomenon and related mitigation measures. Geographica Polonica 87(4), 505-516.

MODIS. (2019). LP DAAC Data Catalog of MOD 11_L2 v006 MODIS/Terra Land Surface Temperature/ Emissivity Product. https://lpdaac.usgs.gov/products/ mod11_12v006/. (accessed: April 10, 2019). 
Moriasi, D. N., Arnold, J. G., Van Liew, M. W., Bingner, R. D., Harmel, R. D. and Veith, T. L. (2007). Model evaluation guidelines for systematic quantification of accuracy in watershed simulations. Transactions of the Asabe 50(3), 885-900.

Parastatidis, D., Mitraka, Z., Chrysoulakis, N. and Abrams, M. (2017). Online global land surface temperature estimation from Landsat. Remote Sensing 9(12), 1208.

OGD Vienna. (2019). Open Government Data Vienna. Data Source: City of Vienna - data.wien.gv.at. (accessed: January 30, 2019).

Pernigotto, G., Prada, A., Cóstola, D., Gasparella, A. and Hensen, J.L.M. (2014). Multi-year and reference year weather data for building energy labelling in North Italy climates. Energy and Buildings 72, 62-72.

Pichierri, M., Bonafoni, S. and Biondi, R. (2012). Satellite air temperature estimation for monitoring the canopy layer heat island of Milan. Remote Sensing of Environment 127, 130-138.

Remote_Sensing. (2019). http://rslab.gr/downloads_ LandsatLST.html/. (accessed: December 24, 2018).

Stewart, I. D. and Oke, T. R. (2012). Local climate zones for urban temperature studies. Bulletin of the American Meteorological Society, 93, 1879-1900.

Taheri, M., Tahmasebi, F., \& Mahdavi, A. (2013). A case study of optimization-aided thermal building performance simulation calibration. Proceedings of BS2013: 13th Conference of International Building Performance Simulation Association.Chambery (France), 26-28 August 2013.

USGS. (2019). U.S. Geological Survey (USGS). https://www.usgs.gov/. (accessed: January 25, 2019).

Vienna in Figures. (2018). https://www.wien.gv.at/ statistik/pdf/viennainfigures-2018.pdf/. (accessed: January 27, 2019).
Voogt, J. A. and Oke, T. R. (1997). Complete urban surface temperatures. Journal of Applied Meteorology $36,1117-1132$.

Vuckovic, M., Kiesel K. and Mahdavi, A. (2015). Toward advanced representations of the urban microclimate in building energy performance simulation. Energy Procedia 78, 3354-3359.

Vuckovic, M., Kiesel K. and Mahdavi, A. (2017). The extent and implications of the microclimatic conditions in the urban environment: A Vienna case study. Sustainability 9(2), 177.

Wan, Z., Hook, S. and Hulley, G. (2015). MOD11_L2 MODIS/Terra Land Surface Temperature/Emissivity 5-Min L2 Swath $1 \mathrm{~km}$ V006 [Data set]. NASA EOSDIS LP DAAC, USGS Earth Resources Observation and Science (EROS) Center, Sioux Falls, South Dakota. doi:10.5067/MODIS/MOD11_L2.006. (accessed: December 08, 2018).

Willmott, C. J. (1984). On the Evaluation of Model Performance in Physical Geography. In Gaile, G. L., Willmott, C. J. Spatial Statistics and Models. Springer Science-Business Media, B. V. Dordrecht, (Netherlands).

Young, N. E., Anderson, R. S, Chignell, S. M., Vorster, A. G., Lawrence, R. and Evangelista, P. H. (2017). A survival guide to Landsat preprocessing. Ecology 98(4), 920-932.

Zakšek, K. and Schroedter-Homscheidt, M. (2009). Parameterization of air temperature in high temporal and spatial resolution from a combination of the SEVIRI and MODIS instruments. ISPRS Journal of Photogrammetry and Remote Sensing 64(4), 414 421.

ZAMG. (2019). Central Institute of Meteorology and Geodynamics, ZAMG. https://www.zamg.ac.at/ $\mathrm{cms} / \mathrm{de} / \mathrm{klima} / \mathrm{messnetze/datenpruefung/.} \mathrm{(accessed:}$ 27 January, 2019). 